\title{
Hematologic, Blood Gas, Cardiac Biomarkers and Serum Biochemical Parameters in Calves with Atresia Coli and Theirs Relationship with Prognosis
}

\author{
Alparslan Coşkun ${ }^{1}$, Ugur Aydogdu' ${ }^{2}$, Semih Altan $^{3}$, Muharrem Erol $^{4}$, Hanifi Erol ${ }^{5}$, \\ Hasan Guzelbektes ${ }^{6,7}$ \& Ismail Sen ${ }^{6,8}$
}

\begin{abstract}
Background: Atresia coli is an intestinal anomaly. Generally, absence of defecation in calves less than 10 days old, diminishing appetite, progressing abdominal distention and time-developing depression are reported in atresia coli. Although a calf consumes its milk normally in first days, loss of appetite develops over time. Occasional minor pain indications are observed. The objective of this study was to evaluate of hematologic, blood gases, cardiac biomarkers and serum biochemical parameters before operation in calves with atresia coli, and to investigate relationship with prognosis of these parameters. Materials, Methods \& Results: Thirty calves with atresia coli and 6 healthy calves for control were used as material. Poor suction reflex, anorexia, dehydration, abdomen-kicking, frequent leg movement, abdominal distension and depression were observed in calves brought to the clinic. Some calves presented swashing sound depending on content of intestines when abdomen was shaken. Intestine atresia was diagnosed by history and clinical examination. After clinical examination, operation was performed. All calves were observed during 10 days after operation. Fifteen of 30 calves died during 10 days after operation. The blood lactate, WBC, LDH and CK-MB levels in non-surviving calves with atresia coli were significantly higher compared to control calves. The venous blood $\mathrm{pH}$ level was significantly lower in non-surviving calves compared to surviving calves. In addition, when compared to the control group, the blood $\mathrm{pCO}_{2}$ level was significantly higher in non-surviving and surviving calves with atresia coli while the $\mathrm{pO}_{2}$ and $\mathrm{O}_{2}$ saturation levels were significantly lower. Discussion: In calves with intestinal atresia, hematologic parameters are normal in first $48 \mathrm{~h}$ of disease. However, leukocytosis and shift to the left have been reported over time. However, leukocytosis due to peritonitis, bacterial overgrowth, etc. have been reported over time. It was seen that leukocyte numbers of non-surviving calves with atresia coli in this study were significantly higher, but leucocyte increase in surviving calves was seen to be statistically insignificant. Leukocyte increased in non-surviving calves with atresia may be associated with excessive bacterial reproduction and peritonitis. Blood lactate level is a commonly used marker for severity of disease in humans and lactate has a prognostic value in adult horses with colic and foals with critical disease. In this study, lactate level in non-surviving calves with atresia coli was significantly higher with respect to surviving calves and control calves. In this result, lactate can be evaluated as a prognostic indicator in calves with atresia coli. Creatine kinase-MB fraction and troponins are used in determination of cardiac damage in veterinary medicine. The fact that serum blood cTnI and CK-MB levels of non-surviving calves with intestinal atresia in this study were higher than surviving calves with atresia coli and control calves suggested that endotoxemia related cardiac damage may have developed. Surgical operation is necessary in the treatment of intestinal atresia. It was determined that the importance of calves age and colon integrity during time of surgical operation in survival of calves with atresia coli. The studies showed that survival rate in surgical operation conducted on calves under 3 days old was higher than calves over 5 day-old. Average of age of non-surviving calves with atresia coli in this study (4.67 \pm 1.23 days) was higher than average of age of surviving calves with atresia coli (3.27 \pm 0.51 days). It was also observed in our study that elapsed time affected prognosis of calves negatively. Thus, performing surgical operations as soon as possible may raise survival rate of calves with intestinal atresia as stated in previous studies.
\end{abstract}

Keywords: calf, atresia coli, biochemical parameters, cardiac biomarker.

${ }^{1}$ Department of Internal Medicine, Faculty of Veterinary Medicine, Cumhuriyet University, Sivas, Turkey. ${ }^{2}$ Department of Internal Medicine, Faculty of Veterinary Medicine, Balikesir University, Balikesir, Turkey. ${ }^{3}$ Department of Surgery, Faculty of Veterinary Medicine, Dicle University, Diyarbakir, Turkey. ${ }^{4}$ Department of Surgery, Faculty of Veterinary Medicine, Balikesir University, Balikesir, Turkey. ${ }^{5}$ Department of Surgery, Faculty of Veterinary Medicine, Erciyes University, Kayseri, Turkey. ${ }^{6}$ Department of Internal Medicine, Faculty of Veterinary Medicine, Selcuk University, Konya, Turkey. ${ }^{7}$ Department of Internal Medicine, Faculty of Veterinary Medicine, Kyrgyz Turkish Manas University, Bishkek, Kyrgyzstan. ${ }^{8}$ Department of Internal Medicine, Faculty of Veterinary Medicine, Near East University, Lefkosa, Nicosia, Cyprus. CORRESPONDENCE: A. Coskun [acoskun@ cumhuriyet. edu.tr - Fax: +90 (346) 2191812]. Department of Internal Medicine, Faculty of Veterinary Medicine, Cumhuriyet University. 58140 Sivas, Turkey. 
A. Coşkun, U. Aydogdu, S. Altan, et al. 2017. Hematologic, Blood Gas, Cardiac Biomarkers and Serum Biochemical Parameters in Calves with Atresia Coli and Theirs Relationship with Prognosis.

Acta Scientiae Veterinariae. 45: 1496

\section{INTRODUCTION}

Intestinal atresia is defined as the atresia of various segments of intestinal in calves. Intestinal atresia can be seen in anus and/or rectum, jejunum, colon and ileum. Atresia ani and atresia coli are most commonly seen form of atresia. The reason of atresia coli is not known clearly. However, genetic and iatrogenic reasons are suggested $[1,7,12]$. Atresic colon structure is an important congenital abnormality. These abnormalities are classified as membrane atresia (type I), cord atresia (type II), blind-end atresia (type III), loop-type blind atresia (type IV), multiple atresia (type V), atresia ani et recti (type VI) [7].

Complete blood count may be used for suggestion about certain disease processes and detection of prognosis in case physical examination results are uncertain [14]. Blood gas analysis may be helpful in evaluation of underlying disease processes and severity of disease. Moreover, blood gas analyses may also guide emergency interventions (such as IV fluid administrations, oxygen therapy, electrolyte supplement, positive ventilation) [13]. Cardiac biomarkers are commonly used in humans and animals for detection of cardiac damage $[25,27]$. Cardiac biomarkers (cTn-I, CK-MB) are stated to be used in calves for detection of cardiac damage $[2,9]$.

The aim of the study was to determine hematologic, blood gas, cardiac biomarkers and serum biochemical parameters in calves with atresia coli and theirs relationship with prognosis.

\section{MATERIALS AND METHODS}

\section{Animals}

This study was conducted with 1-10 day-old 30 calves with atresia coli (23 male, 5 female, 2 with no records) brought to Large Animal Clinic of Faculty of Veterinary Medicine of Selcuk University and 1-10 day-old 6 healthy calves of Holstein breed for control. Majority of calves with atresia coli were from Holstein race (28 Holstein, 1 Brown Swiss, 1 with no records). In anamnesis, owners of calves indicated that consumption of colostrum and milk by calves, no meconium or defecation, occasional abdominal distension, pain findings and mucus coming from rectum were observed.

\section{Clinical findings}

Poor suction reflex, anorexia, dehydration, abdomen-kicking, frequent leg movement, abdominal distension and depression were observed in calves brou- ght to the clinic. Some calves presented swashing sound depending on content of intestines when abdomen was shaken. According to anamnesis and clinical findings, calves with intestinal atresia diagnosis were operated. All calves were followed for 10 days after operation.

\section{Blood collection and blood analyses}

Blood samples were drawn from V. Jugularis of calves with $2 \mathrm{~mL}$ of blood to heparinized injectors for blood gas analyses, $2 \mathrm{~mL}$ of blood to K3 EDTA tubes for hematological analyses and to $5 \mathrm{~mL}$ gel polyethylene tubes without anticoagulants for biochemical analyses. Blood gas analysis of the calves $\left(\mathrm{pH}, \mathrm{pO}_{2}\right.$, $\mathrm{pCO}_{2}$, glucose, $\mathrm{Na}+, \mathrm{K}+, \mathrm{iCa}+2$, lactate, $\mathrm{HCO}_{3-}, \mathrm{BE}$ and $\mathrm{O}_{2}$ sat levels) were measured in blood gas analyzer (GEM Premier Plus) ${ }^{1}$ within 15 min. WBC, RBC, HCT, Hg, PLT levels of the calves were determined with hematologic analyzer (MS4 VET) $)^{2}$ within 30 min. The tubes without anticoagulant were incubated for 30 min in the room temperature, then centrifuged for 5 min at $2500 \mathrm{~g}$ and serum samples were removed and stored at $-20^{\circ} \mathrm{C}$ until analyzed. Serum aspartate aminotransferase (AST), lactate dehydrogenase (LDH), blood urea nitrogen (BUN), total protein (TP), albumin $(\mathrm{ALB})$, creatinine $(\mathrm{CR})$, creatine kinase $(\mathrm{CK})$, creatine kinase- myocardial band (CK-MB) concentrations were determined using auto analyzer (BT 3000 plus) ${ }^{3}$ with commercial kits, and cardiac troponin I (cTn-I) levels were determined using a chemiluminescent immunoassay (Siemens Advia Centaur XP) ${ }^{4}$.

\section{Statistical analysis}

Data were expressed as mean \pm SE. The level of statistical significance was set at $P<0.05$. ANOVA and Tukey multiple range tests were used to determine the difference between the groups. The SPSS software program (Version 15.0) ${ }^{5}$ was used for statistical analysis.

\section{RESULTS}

Fifteen of 30 calves died during 10 days after operation. The venous blood $\mathrm{pH}$ level was significantly lower $(P<0.05)$ in non-surviving calves compared to surviving calves. In addition, when compared to the control group, the blood $\mathrm{pCO}_{2}$ level was significantly higher in surviving and non-surviving calves with atresia while the $\mathrm{pO}_{2}$ and $\mathrm{sO}_{2}$ levels were significantly lower. The mean age of non-surviving calves was 4.67 days. However, the mean age of surviving calves was 3.27 days. The blood lactate, WBC, LDH and 
CK-MB levels in non-surviving calves with intestinal atresia were significantly higher $(P<0.05)$ compared to control calves (Tables $1 \& 2$ ).

\section{DISCUSSION}

Atresia coli is an intestinal anomaly that results in death when untreated. Death can occur within a few days due to autointoxication in the intestine [21]. Atresia coli is reported to be common in dairy calves, particularly in calves of Holstein breed [17]. Vital findings in calves with atresia coli are normal during first days of life; however, findings such as loss of appetite, depression, abdominal distension develop over time. In some cases, intense mucus coming from rectum may be seen. After 5-6 days, calves are weak (depressive) and in lying position. Rupture in intestines and acute diffuse peritonitis may be occur [21]. In this study, the fact that the calves are of Holstein breed, there is no defecation, abdominal distension and pain indications are seen shows similarity with previous studies [17,21].

In calves with intestinal atresia, hematologic parameters are normal in first 48 hours of disease. It is indicated that excessive bacterial reproduction, fluid accumulation, endotoxemia, peritonitis and dehydration depending on necrosis in intestines, leukocytosis and degenerative left shift can develop as time advances $[1,21]$. It was seen that leukocyte numbers of non-surviving calves with atresia coli in this study were significantly higher $(P<0.05)$, but leukocyte increase in surviving calves was seen to be statistically insignificant (Table 1). Leukocyte increased in non-surviving calves with atresia may be associated with excessive bacterial reproduction, peritonitis and endotoxemia.

Body temperatures, respiration and circulation values of calves with intestinal atresia are reported to be physiological at the beginning, and it is reported that hypercapnia and tachycardia depending on developing abdominal tension and endotoxemic shock may occur [5,17,23]. Koc et al. [17] determined disruption in tissue perfusion depending on atresia and peritonitis in calves with intestinal atresia, and decrease in venous blood $\mathrm{pO}_{2}$ and $\mathrm{O}_{2}$ saturation as a result of insufficiency in $\mathrm{O}_{2}$ distribution. Moreover, it is expressed that mild metabolic acidosis and dehydration may develop in calves with atresia coli $[6,17,23]$. Similarly, blood $\mathrm{pCO}_{2}$ level was significantly higher in calves with atresia coli compared to control group in this study; however, $\mathrm{pH}, \mathrm{pO}_{2}$ and $\mathrm{O}_{2}$ saturation levels were low (Table 1). It was evaluated to be associated with respiratory acidosis and endotoxemia severity developed in non-surviving calves with atresia coli.

Blood lactate level is a commonly used marker for severity of disease in humans and lactate has a prognostic value in adult horses with colic and foals with critical disease [24]. L-lactic acidosis is thought to result from anaerobic glycolysis due to dehydration or endotoxemia-dependent poor tissue perfusion and reduced clearance of L-lactate from liver [10,19,24]. D-lactate is of microbial origin [4] and is not produced in mammalian cells. D-lactic acidosis results from fermentation of lactose in intestines (especially in large intestines) [19]. Increased blood lactate level has been found to be associated with morbidity and mortality [3]. In addition, hyperlactatemia observed in admission to intensive care unit has been associated with high mortality in children [11]. In this study, lactate level in non-surviving calves with atresia coli was significantly higher $(P<0.05)$ with respect to surviving calves and control calves. The fact that hematocrit and total protein concentrations of calves with atresia are normal has been associated with bacterial overgrowth in intestines and/or endotoxemia, not dehydration, as the source of hyperlactatemia. In this result, lactate can be evaluated as a prognostic indicator in calves with atresia coli.

Muscle damage and necrosis cause an obvious increase in LDH, AST and CK activity [22]. Serum AST activity shows extended tissue variation, however it is most commonly present in liver and muscle tissue. In this study presented, the fact that serum LDH, AST and CK enzyme activities in calves with atresia show increase compared to control group may be resulted from intestine damages in the region with atresia. It was thought that increase in levels of these enzymes was a useful parameter in decision of operation for calves with atresia coli.

In recent years, creatine kinase-MB fraction (CK-MB) and troponins are used in determination of cardiac damage in veterinary medicine [16]. Cardiac damage in cattle's are detected with increased cardiac troponin levels in various diseases including monensin toxicity [26], traumatic reticulopericarditis $[8,18]$, foot-and-mouth disease $[9,15]$ and endotoxemia [20]. The fact that serum blood cTnI and CK-MB levels of non-surviving calves with intestinal atresia in this study were 
A. Coşkun, U. Aydogdu, S. Altan, et al. 2017. Hematologic, Blood Gas, Cardiac Biomarkers and Serum Biochemical Parameters in Calves with Atresia Coli and Theirs Relationship with Prognosis.

Acta Scientiae Veterinariae. 45: 1496

Table 1. Blood gas and hematologic parameters before operations in calves with intestinal atresia.

\begin{tabular}{cccc}
\hline Parameter & $\begin{array}{c}\text { Non-surviving calves } \\
(\mathrm{n}=15) \\
\text { Mean } \pm \text { SEM }\end{array}$ & $\begin{array}{c}\text { Surviving calves } \\
(\mathrm{n}=15) \\
\text { Mean } \pm \text { SEM }\end{array}$ & $\begin{array}{c}\text { Control calves } \\
(\mathrm{n}=6) \\
\text { Mean } \pm \text { SEM }\end{array}$ \\
\hline $\mathrm{pH}$ & $7.34 \pm 0.02^{\mathrm{b}}$ & $7.43 \pm 0.01^{\mathrm{a}}$ & $7.40 \pm 0.01^{\mathrm{ab}}$ \\
$\mathrm{pCO}_{2}(\mathrm{mmHg})$ & $47.00 \pm 2.10^{\mathrm{a}}$ & $48.60 \pm 1.59^{\mathrm{a}}$ & $38.52 \pm 1.49^{\mathrm{b}}$ \\
$\mathrm{pO}_{2}(\mathrm{mmHg})$ & $19.33 \pm 0.91^{\mathrm{b}}$ & $23.47 \pm 2.52^{\mathrm{b}}$ & $34.92 \pm 1.47^{\mathrm{a}}$ \\
$\mathrm{Na}^{+}(\mathrm{mmol} / \mathrm{L})$ & $143.13 \pm 1.49$ & $141.53 \pm 1.07$ & $144.00 \pm 1.10$ \\
$\mathrm{~K}^{+}(\mathrm{mmol} / \mathrm{L})$ & $4.42 \pm 0.22^{\mathrm{a}}$ & $4.23 \pm 0.17^{\mathrm{a}}$ & $3.39 \pm 0.12^{\mathrm{b}}$ \\
$\mathrm{iCa}^{+2}(\mathrm{mmol} / \mathrm{L})$ & $0.95 \pm 0.04$ & $1.00 \pm 0.04$ & $1.03 \pm 0.04$ \\
$\mathrm{Glucose}^{\mathrm{a}}(\mathrm{mg} / \mathrm{dL})$ & $71.08 \pm 9.79$ & $93.69 \pm 7.59$ & $78.33 \pm 9.11$ \\
$\mathrm{Lactate}(\mathrm{mmol} / \mathrm{L})$ & $5.65 \pm 1.08^{\mathrm{a}}$ & $3.09 \pm 0.61^{\mathrm{ab}}$ & $0.60 \pm 0.15^{\mathrm{b}}$ \\
$\mathrm{HCO}^{3-}(\mathrm{mmol} / \mathrm{L})$ & $26.29 \pm 2.03$ & $32.26 \pm 1.17$ & $26.13 \pm 0.90$ \\
$\mathrm{BE}^{(\mathrm{mmol} / \mathrm{L})}$ & $0.67 \pm 2.38$ & $7.93 \pm 1.24$ & $1.23 \pm 0.65$ \\
$\mathrm{O}_{2} \mathrm{sat}(\%)$ & $28.50 \pm 3.69^{\mathrm{b}}$ & $37.38 \pm 5.33^{\mathrm{b}}$ & $70.85 \pm 1.96^{\mathrm{a}}$ \\
$\mathrm{WBC}^{\mathrm{b}}\left(10^{3} / \mu \mathrm{L}\right)$ & $17.32 \pm 1.83^{\mathrm{a}}$ & $13.82 \pm 1.63^{\mathrm{ab}}$ & $9.30 \pm 0.57^{\mathrm{b}}$ \\
$\mathrm{RBC}^{\mathrm{b}}\left(10^{6} / \mu \mathrm{L}\right)$ & $7.43 \pm 0.59$ & $7.47 \pm 0.49$ & $7.03 \pm 0.55$ \\
$\mathrm{HCT}(\%)$ & $30.68 \pm 2.62$ & $28.41 \pm 1.85$ & $25.33 \pm 1.89$ \\
$\mathrm{HGB}(\mathrm{g} / \mathrm{dL})$ & $9.41 \pm 0.66$ & $9.49 \pm 0.46$ & $9.27 \pm 0.25$ \\
$\mathrm{PLT}\left(10^{3} / \mu \mathrm{L}\right)$ & $378.80 \pm 52.93$ & $365.85 \pm 63.96$ & $449.67 \pm 31.08$ \\
\hline
\end{tabular}

pH: concentration of hydrogen ions, $\mathrm{pCO}_{2}$ : partial pressure of carbon dioxide, $\mathrm{pO}_{2}$ : partial pressure of oxygen, $\mathrm{Na}^{+}$: sodium, $\mathrm{K}^{+}$: potassium, iCa $\mathrm{i}^{+2}$ : ionized calcium, $\mathrm{HCO}_{3}^{-}$: bicarbonate, $\mathrm{BE}$ : base excess, $\mathrm{O}_{2}$ sat. \%: oxygen saturation, WBC: white blood cell, RBC: red blood cell, HCT: hematocrit, HGB: hemoglobin, PLT: platelet. Different letters in the same rows $(a, b)$ are statistically significant $(P<0.05)$.

Table 2. Mean serum concentrations of serum biochemical parameters and cardiac biomarkers in calves with intestinal atresia.

\begin{tabular}{|c|c|c|c|}
\hline Parameter & $\begin{array}{l}\text { Non-surviving calves } \\
(\mathrm{n}=15) \\
\text { Mean } \pm \text { SEM }\end{array}$ & $\begin{array}{l}\text { Surviving calves } \\
\qquad(\mathrm{n}=15) \\
\text { Mean } \pm \text { SEM }\end{array}$ & $\begin{array}{l}\text { Control calves } \\
\qquad(\mathrm{n}=6) \\
\text { Mean } \pm \text { SEM }\end{array}$ \\
\hline BUN (mg/dL) & $32.47 \pm 6.98$ & $30.93 \pm 5.61$ & $16.17 \pm 1.90$ \\
\hline $\mathrm{CR}(\mathrm{mg} / \mathrm{dL})$ & $2.35 \pm 0.57$ & $1.63 \pm 0.20$ & $0.92 \pm 0.06$ \\
\hline AST (U/L) & $87.80 \pm 14.70$ & $55.80 \pm 7.19$ & $48.60 \pm 8.83$ \\
\hline CK (U/L) & $378.40 \pm 103.28$ & $194.50 \pm 53.01$ & $163.50 \pm 22.38$ \\
\hline LDH (U/L) & $1018,67 \pm 138.58^{a}$ & $839.20 \pm 125.33^{\mathrm{ab}}$ & $347.40 \pm 21.52^{b}$ \\
\hline $\operatorname{ALB}(g / d L)$ & $2.68 \pm 0.11^{\mathrm{ab}}$ & $2.53 \pm 0.08^{b}$ & $3.03 \pm 0.06^{\mathrm{a}}$ \\
\hline $\mathrm{TP}(\mathrm{g} / \mathrm{dL})$ & $5.98 \pm 0.25$ & $5.89 \pm 0.15$ & $6.44 \pm 0.13$ \\
\hline CK-MB (U/L) & $153.73 \pm 24.60^{\mathrm{a}}$ & $78.57 \pm 9.96^{\mathrm{ab}}$ & $53.50 \pm 12.76^{\mathrm{b}}$ \\
\hline Troponin-I (ng/mL) & $0.22 \pm 0.100$ & $0.03 \pm 0.004$ & $0.01 \pm 0.007$ \\
\hline Age (Day) & $4.67 \pm 1.23$ & $3.27 \pm 0.51$ & $10.66 \pm 1.69$ \\
\hline
\end{tabular}

BUN: Blood urea nitrogen, CR: creatinine, AST: aspartate aminotransferase, CK: creatine kinase, LDH: lactate dehydrogenase, ALB: albumin, TP: total protein, CK-MB: creatine kinase- myocardial band. Different letters in the same rows $(\mathrm{a}, \mathrm{b})$ are statistically significant $(P<0.05)$. 
A. Coşkun, U. Aydogdu, S. Altan, et al. 2017. Hematologic, Blood Gas, Cardiac Biomarkers and Serum Biochemical Param-

higher (Table 2) than surviving calves with atresia coli and control calves suggested that endotoxemia related cardiac damage may have developed.

Surgical operation is necessary in the treatment of intestinal atresia. It was determined that the importance of calves age and colon integrity during time of surgical operation in survival of calves with atresia coli. The studies showed that survival rate in surgical operation conducted on calves under 3 days old was higher than calves over 5 days old [1]. Average of age of non-surviving calves with atresia coli in this study ( $4.67 \pm 1.23$ days) was higher than average of age of surviving calves with atresia coli $(3.27 \pm 0.51$ days). It was also observed in our study that elapsed time affected prognosis of calves negatively. Thus, performing surgical operations as soon as possible may raise survival rate of calves with intestinal atresia as stated in previous studies.

\section{CONCLUSIONS}

In conclusion, important changes were observed in blood gas, hematologic, biochemical and cardiac parameters in calves with atresia coli. Also, according to results of this study, it was concluded that co-evaluation of age of calf, blood lactate and WBC levels and CK-MB and LDH enzyme concentrations in decision of operation for calves with atresia coli would be beneficial.

\author{
MANUFACTURERS \\ ${ }^{1}$ Instrumentation Laboratory Inc. Bedford, MA, USA. \\ ${ }^{2}$ Melet Schlosing Laboratories. Osny, France. \\ ${ }^{3}$ Biotechnical Inc. SPA. Rome, Italy. \\ ${ }^{4}$ Siemens AG. Erfurt, Germany. \\ ${ }^{5}$ SPSS Inc. Chicago, IL, USA.
}

Declaration of interest. The authors report no conflicts of interest. The authors alone are responsible for the content and writing of the paper.

\section{REFERENCES}

1 Anderson D.E. \& Ring D.M. 2009. Current Veterinary Therapy: Food Animal Practice. 5th edn. Saint Louis: Saunders Elsevier, pp.122-125.

2 Aydogdu U., Yildiz R., Guzelbektes H., Coskun A. \& Sen I. 2016. Cardiac biomarkers in premature calves with respiratory distress syndrome. Acta Veterinaria Hungarica. 64(1): 38-46.

3 Bakker J., Nijsten M.W.N. \& Jansen T.C. 2013. Clinical use of lactate monitoring in critically ill patients. Annals Intensive Care. 3: 12.

4 Christopher M., Broussard J., Fallin C., Drost N.J. \& Peterson M.E. 1995. Increased serum D- lactate associated with diabetic ketoacidosis. Metabolism 44: 287-290.

5 Constable P.D., Rings D.M., Hull B.L., Hoffsis G.E. \& Robertson J.T. 1989. Atresia coli in calves, 26 cases (19771987). Journal of American Veterinary Medical Association. 195(1): 118-123.

6 Dreyfuss D.J. \& Tulleners E.P. 1989. Intestinal atresia in calves, 22 cases (1978-1988). Journal of American Veterinary Medical Association. 195(4): 508-513.

7 Gorgul O.S., Yavru N., Atalan G., Demirkan I., Kilic N., Sarierler M., Tas A., Altug M.E., Cecen G., Kibar M., Pekcan Z., Salci H. \& Kurum B. 2012. Veteriner Özel Cerrahi. Malatya: Medipres, pp.255-308.

8 Gunes V., Atalan G., Citil M. \& Erdogan H.M. 2008. Use of cardiac troponin kits for the qualitative determination of myocardial cell damage due to traumatic reticuloperitonitis in cattle. Veterinary Record. 162: 514-517.

9 Gunes V., Erdogan H.M., Citil M. \& Ozcan K. 2005. Assay of cardiac troponins in the diagnosis of myocardial degeneration due to foot-and-mouth disease in a calf. Veterinary Record. 156: 714-715.

10 Guzelbektes H., Coskun A. \& Sen I. 2007. Relationship between the degree of dehydration and the balance of acidbased changes in dehydrated calves with diarrhoea. Bulletin of the Veterinary Institute in Pulawy. 51: 83-87.

11 Hatherill M., Mcintyre A.G., Wattie M. \& Murdoch I.A. 2000. Early hyperlactataemia in critically ill children. Intensive Care Medicine. 26(3): 314-318.

12 House J.K. \& Gunn A.A. 2009. Manifestations and Management of Disease in Neonatal Ruminants. In: Smith B.P. (Ed). Large Animal Internal Medicine. 4th edn. St. Louis: Mosby Elsevier, pp.333-366.

13 Irizarry R. \& Reiss A. 2009. Arterial and venous blood gases: Indications, interpretations, and clinical applications. Compendium Continuing Education for Veterinarians. 31: 1-7. 
A. Coşkun, U. Aydogdu, S. Altan, et al. 2017. Hematologic, Blood Gas, Cardiac Biomarkers and Serum Biochemical Parameters in Calves with Atresia Coli and Theirs Relationship with Prognosis. Acta Scientiae Veterinariae. 45: 1496.

14 Jones M.L. \& Allison R.W. 2007. Evaluation of the ruminant complete blood cell count. Veterinary Clinics of North America: Food Animal Practice. 23: 377-402.

15 Karapinar T., Dabak D.O., Kuloglu T. \& Bulut H. 2010. High cardiac troponin I plasma concentration in a calf with myocarditis. Canadian Veterinary Journal. 51: 397-399.

16 Kemp M., Donovan J., Higham H. \& Hooper J. 2004. Biochemical markers of myocardial injury. British Journal of Anaesthesia. 93: 63-73.

17 Koc Y., Alkan F., Ceylan C. \& Birdane F.M. 2001. Evaluation of clinical and surgical approaches in 22 calves with atresia coli (in Turkish). Avrasya Veteriner Bilimleri Dergisi. 17(1): 27-34.

18 Mellanby R.J., Henry J.P., Cash R., Ricketts S.W., Bexiga R., Truyers I. \& Mellor D.J. 2009. Serum cardiac troponin I concentrations in cattle with cardiac and noncardiac disorders. Journal of Veterinary Internal Medicine. 23: 926-930.

19 Omole O.O., Nappart G. \& Naylor J.M. 2001. Both L-and D-lactate contribute to metabolic acidosis in diarrheic calves. Journal of Nutrition. 131: 2128-2131.

20 Peek S.F., Apple F.S., Murakami M.A., Crump P.M. \& Semrad S.D. 2008. Cardiac isoenzymes in healthy Holstein calves and calves with experimentally induced endotoxemia. Canadian Journal of Veterinary Research. 72: 356-361.

21 Radostits O.M., Gay C.C., Hinchcliff K.W. \& Constable P.D. 2007. Veterinary Medicine. A textbook of the diseases of cattle, sheep, pigs, goats, and horses. 10th edn. London: Saunders Elsevier, pp.280-281.

22 Russell K.E. \& Roussel A.J. 2007. Evaluation of the ruminant serum chemistry profile. Veterinary Clinics of North America: Food Animal Practice. 23: 403-426.

23 Smith D.F., Ducharme N.G., Fubini S.L., Donawick W.J. \& Erb H.N. 1991. Clinical management and surgical repair of atresia coli in calves, 66 cases (1977-1988). Journal of the American Veterinary Medical Association. 199(9): 1185-1190.

24 Tennent-Brown B. 2014. Blood lactate measurement and interpretation in critically ill equine adults and neonates. Veterinary Clinics of North America: Equine Practice. 30(2): 399-413.

25 Undhad V.V., Fefar D.T., Jivani B.M., Gupta H., Ghodasara D.J., Joshi B.P. \& Prajapati K.S. 2012. Cardiac troponin: an emerging cardiac biomarker in animal health. Veterinary World. 5: 508-511.

26 Varga A., Schober K.E., Holloman C.H., Stromberg P.C., Lakritz J. \& Rings D.M. 2009. Correlation of serum cardiac troponin I and myocardial damage in cattle with monensin toxicosis. Journal of Veterinary Internal Medicine. 23: 1108-1116.

27 Vijlbrief D.C., Benders M.J.N.L., Kemperman H., Van Bel F. \& De Vries W.B. 2012. Cardiac biomarkers as indicators of hemodynamic adaptation during postasphyxial hypothermia treatment. Neonatology. 102: 243-248.

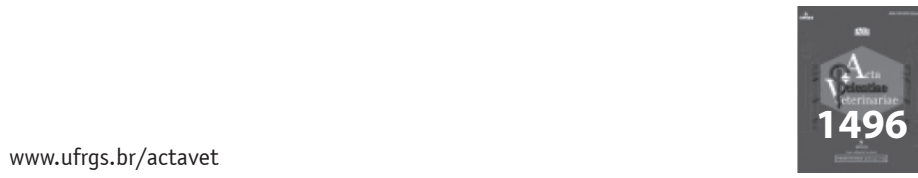

